\title{
Saias, selins e sensibilidades: movimentos feministas e bens de consumo
}

\section{Skirts, saddles and sensibilities: feminist movements and consumer goods}

Everardo Rocha ${ }^{1}$

Beatriz Beraldo ${ }^{2}$

Resumo: Este artigo tem como objetivo apresentar, em perspectiva histórica, momentos de estreita vinculação entre a atuação política do feminismo e as práticas de consumo modernas. O enfoque central será a análise do surgimento da bicicleta como bem de consumo. Ainda que pensada para homens, foi - nos Estados Unidos e em vários países europeus - apropriada pelas mulheres, que rapidamente se transformaram nas suas principais consumidoras. A chegada desse bem de consumo foi relacionada às lutas feministas por emancipação, provocando uma onda de transformações sociais.

Palavras-chave: consumo; comunicação; feminismo; bicicleta.

Abstract: This article aims to show, in historical perspective, moments of close linkage between the political action of feminism and the modern consumer practices. The central focus will be the analysis of the emergence of the bicycle as a consumer good. Although it was thought for men, bicycle was - in the United States and in several European countries - appropriated by women, who quickly became its main consumers. The arrival of this good of consumption was related to the feminist struggles for emancipation, provoking a wave of social transformations.

Key-words: consumption; communication; feminism; bicycle.

1 Pontifícia Universidade Católica do Rio de Janeiro (PUC-Rio). Rio de Janeiro, RJ, Brasil. https://orcid.org/0000-0001-5821-1917.E-mail: everardo@puc-rio.br

2 Pontifícia Universidade Católica do Rio de Janeiro (PUC-Rio). Rio de Janeiro, RJ, Brasil. https://orcid.org/0000-0003-1 126-8240. E-mail: biaberaldob@gmail.com 


\section{Introdução}

O objetivo deste artigo é examinar as relações históricas e as parcerias estabelecidas entre movimentos sociais - os feministas, ${ }^{3}$ em especial - e as representações e práticas de consumo. Nessa investigação, de caráter bibliográfico e documental, analisamos principalmente a emergência de um determinado bem - a bicicleta - e suas apropriações pelas lutas libertárias das mulheres, tanto no que diz respeito às suas possibilidades de locomoção e ampliação de espaços de trânsito quanto à redefinição das fronteiras de seus corpos.

A partir de uma análise textual (BAUER; GASKELL, 2002; DUARTE; BARROS, 2009) fundamentada na significativa presença de imagens e textos de anúncios publicitários e notícias de jornais norte-americanos do final do século XIX, a pesquisa ressalta que o fenômeno do consumo, via de regra percebido a partir de um olhar moralista e de um viés que o coloca como politicamente reacionário, se tornou, em certas circunstâncias históricas, aliado dos movimentos pela emancipação das mulheres (ROCHA; FRID; CORBO, 2015). O caso da bicicleta é exemplar nesse sentido, justificando sua escolha como objeto de análise, pois esse bem de consumo articulou lutas femininas na esfera pública - pela liberdade de circulação - e privada - no que concerne ao controle do desejo sexual.

\section{Acadêmicos e advogados}

A crítica ao consumo a partir de uma visão moralista que, por vezes, até o vê como "doença” é algo corriqueiro no senso comum, em discursos midiáticos e mesmo em parte da intelligentsia como contraponto ao viés hedonista sobre o fenômeno (ROCHA, 2005). De fato, trata-se de uma antiga tensão que acaba por marcar muitas das interpretações sobre os significados e impactos dos fenômenos sociais. No caso daqueles relacionados ao universo da comunicação - consumo, televisão,

3 Uma revisão mais detida dos incontáveis textos e múltiplas posições do complexo universo de estudos feministas ultrapassaria em muito os limites deste trabalho. 
publicidade, celulares, videogames, entre outros -, essa tensão remete ao termo Kulturindustrie, criado por Adorno e Horkheimer no clássico Dialética do esclarecimento (1947). Vinte anos após a primeira publicação da expressão “indústria cultural”, Adorno (1968), em novo ensaio chamado Résumé über Kulturindustrie, ${ }^{4}$ disse que a preferência pela expressão "indústria cultural" como substituta para "cultura de massa" ocorreu visando "[...] excluir de antemão a interpretação que agrada os advogados $^{5}$ da coisa [...]" (ADORNO, 1971, p. 287). Assim, a ideia de indústria cultural visa dar conta do processo de massificação da comunicação ante a acelerada produção de conteúdo midiático nas sociedades altamente industrializadas. Contudo, essa visão apresenta uma sutil redundância que acaba por relativizar a própria perspectiva que pretende atingir. Vejamos: se os seres humanos têm capacidade para transformar a natureza a partir de sistemas simbólicos que elaboram linguagens, técnicas, artefatos, máquinas, indústrias etc., seria possível dizer que toda indústria é cultural, pois é, sempre e necessariamente, vinculada a um plano simbólico. Assim, portanto, a ideia de "indústria cultural" em Adorno, menos do que distinguir um tipo de "indústria" que produziria bens materiais e outra, a cultural, que produziria bens simbólicos, indica que a segunda está submetida aos mesmos interesses econômicos que as demais. Os pensadores frankfurtianos, que visavam se distanciar dos supostos defensores da cultura de massa, revelam, na verdade, outra intenção: a escolha consciente de asseverar seu posicionamento moral e político diante das consequências da comunicação de massa para a sociedade moderno-contemporânea. Nesse sentido, a escolha da expressão "indústria cultural" implica uma perspectiva acusatória - coisa pertinente a advogados (anwälten) e tribunais - diante dos produtos midiáticos e das temáticas da comunicação.

Importa lembrar que a tendência de se posicionar moralmente, escolhendo "um lado" no debate da comunicação de massa, é uma questão central da obra Apocalípticos e integrados, de Umberto Eco (1964). A

\footnotetext{
4 Traduzido para português como "A indústria cultural" (1971).

5 Anwälten em alemão, que significa advogado ou jurista.
} 
partir dessa tensão entre "bem" e "mal" - os integrados e apocalípticos de Eco -, teóricos da comunicação se posicionavam como defensores ou acusadores diante de um réu e, por esse motivo, teciam ideias que, em verdade, lembravam mais atas de absolvição ou condenação que, pelo próprio limite de seus lugares de fala, deixavam de lado o exame mais detido de dimensões fundamentais desses complexos fenômenos. Esse "paradigma do tribunal" polarizou e pode ter sido um dos responsáveis, no caso do consumo, por deixá-lo de fora, por muito tempo, das reflexões e dos debates acadêmicos estrito senso (ROCHA, 1995). Não por acaso, ainda que o fenômeno tenha nomeado a experiência que vivemos - sociedade de consumo -, é um tema pouco estudado pelas ciências sociais e, muitas vezes, embebido de ideologias e/ou envolvimentos emocionais que ora tendem a uma forte acusação, ora o tratam como futilidade que não mereceria o mesmo crédito acadêmico das ditas questões "sérias":

Essa "visão moralista" do consumo se manifesta tanto em discursos simplistas e ingênuos quanto em análises intelectualmente sofisticadas. Porém, tratar o consumo como banalidade ou acusá-lo pelos problemas que enfrentamos obstrui o caminho para análises que buscam compreendê-lo como um fenômeno central da cultura moderno-contemporânea (ROCHA; FRID; CORBO, 2016, p. 14).

Dessa maneira, é com certa frequência que investigadores dos fenômenos sociais encaram a dificuldade da polarização contida em seus temas, o que leva ao risco de transformá-los em "advogados da coisa" ou em coléricos inquisidores. Nosso trabalho, portanto, ao investigar o consumo desde uma perspectiva histórica, contribui, pelo distanciamento mesmo que a temporalidade pode propiciar, para perceber eventos históricos nos quais as lutas das mulheres estabeleceram parcerias com as práticas modernas de consumo.

Assim, começaremos inventariando algumas transformações que o consumo provocou nos poderes estabelecidos, como foram os casos das significativas contribuições da loja de departamento Selfridge's para as lutas das sufragistas na Londres do início do século XX (ROCHA; FRID; CORBO, 2015) ou a aliança entre as feministas norte-americanas e o 
tabagismo no final da década de 1920 (LEAL; FREIRE FILHO; ROCHA, 2016). Este estudo, entretanto, pretende revelar que outro bem de consumo específico - a bicicleta - motivou mudanças nos planos cultural e político, contribuindo decisivamente nas lutas, experiências, sensibilidades e na própria existência de mulheres mais livres das tradições de dominação.

\section{Mulheres e consumo}

A Revolução Industrial é convencionalmente tomada como ponto de partida para a formação da sociedade moderna. O produtivismo, a noção de indivíduo, a consolidação dos poderes do Estado, a prevalência da percepção do tempo como história (ROCHA, 1995), além dos meios de comunicação de massa e do consumo - todas características facilmente reconhecidas na sociedade contemporânea -, foram gestados nas complexas transformações de forças que amalgamaram modos de produção, novos valores culturais, reordenações sociais, trânsitos políticos e sensibilidades em torno do projeto que acabou por configurar o que chamamos, em sentido amplo, de modernidade.

É nesse contexto, já relativamente consolidado, que um novo modelo de negócios comerciais entra em cena: as lojas de departamentos, também conhecidas como grands magasins, que surgem na França, na Inglaterra e nos Estados Unidos da América a partir da segunda metade do século XIX e que ocupam um lugar fundamental no incentivo às vendas, no dispêndio pecuniário e, sobretudo, no consumo tal como hoje o experimentamos:

No nível popular, esse período foi marcado pela democratização do lazer e da moda e pelo surgimento de lojas de departamentos [...], como a Macy's (1858) em Nova York, o Bon Marche (1869), a La Samaritaine (1870) e as Galeries Lafayette (1895) em Paris, a Wanamaker's na Filadelfia (1877) e a Selfridge's em Londres (1909). Elas representaram aquilo que se chamou de "revolução nas vendas" [...] (BURKE, 2008, p. 32). 
A forma como as pessoas adquirem bens se transforma e o consumo passa, a partir de então, a ser experimentado como uma atividade prazerosa. Por isso, no ambiente dos grandes magazines, “[...] pedia-se que os clientes considerassem as compras não como um ato econômico, mas como um evento social e cultural" (RAPPAPORT, 2004, p. 159). Além disso, o uso da imprensa e da publicidade em favor das atividades de compra são alguns aspectos da consolidação de uma cultura que passa a ter no consumo uma de suas práticas mais rotineiras e uma de suas representações mais nitidamente compartilhadas. Os anúncios e cartazes publicitários que divulgavam os grands magasins sobejavam múltiplos estímulos visuais que se reproduziam nas suas vitrines6 e nas experiências de compra no espaço das lojas de departamentos.

Nesse novo contexto, as mulheres começaram a protagonizar a cena do consumo: tanto por serem as principais consumidoras quanto por atuarem como funcionárias contratadas dessas grandes lojas de departamentos. A frequência feminina aos grands magasins era extremamente significativa, pois estes se tornaram um dos primeiros espaços públicos que as mulheres podiam frequentar desacompanhadas: “[...] a loja de departamentos tornou-se interessante para a mídia não apenas pelas mercadorias que vendia, mas por sua definição como uma instituição social e cultural para as mulheres" (RAPPAPORT, 2004, p. 164). Como espaço de trabalho, por volta de 1900, por exemplo, um impressionante número de 250 mil mulheres se empregavam no varejo britânico - área em franco desenvolvimento e que ocupava mais de um terço da mão de obra total daquele país (COX, 2017).

Mais do que isso, a relação entre mulheres e consumo propiciada pelas lojas de departamentos é também marcada por uma aliança política. Nessa parceria inusitada, as feministas da primeira onda, que também ficaram mundialmente conhecidas como suffragettes, se articularam aos grandes magazines para avançar seus projetos políticos:

6 As técnicas de sedução também aparecem nas vitrines das lojas ao permitirem visibilidade aos produtos oferecidos - já que, anteriormente, os consumidores tinham de ir à loja já sabendo o que desejavam adquirir (ROCHA, FRID e CORBO, 2016). 
[...] Em Londres, Paris e diversas cidades dos EUA, as lojas de departamentos sediavam as reuniões das sufragistas ao mesmo tempo que investiam em publicidade nas revistas do movimento. As militantes, à sua maneira, buscavam evidenciar suas feições e elegância feminina com vestidos longos e acessórios, sempre nas cores violeta, branca e verde [...]. Com isso, em via de mão dupla, eram as consumidoras das mesmas lojas de departamentos que as protegiam (ROCHA; FRID; CORBO, 2015).

O caso da Selfridge's é emblemático. A loja de departamentos estabelecida no West End, em Londres, foi ponto de encontro das mulheres que lutavam pelo direito ao voto. É sabido que Gordon Selfridge, o proprietário, tinha posição favorável ao sufrágio feminino e, “[...] em um tom quase feminista, despido de qualquer mensagem manifestamente política, ele [Selfridge] retratou sua loja como o 'rendez-vous' feminino ou como o ponto de encontro público ideal” (RAPPAPORT, 2004, p. 172). Assim, abraçou a causa das suffragettes que, não por acaso, eram também suas consumidoras. Selfridge não apenas permitia reuniões no café da loja como fez também vitrines especiais com cores que homenageavam o movimento. Além disso, publicou anúncios nos periódicos pró-sufrágio produzidos por mulheres, o que significava incentivo financeiro ao movimento (NAVA, 2007). Também no documentário Secrets of Selfridge's (Reino Unido, 2014) e no seriado Mr. Selfridge (Reino Unido, 2013), ambos da rede PBS, vemos a estreita parceria entre a figura de Gordon Selfridge7 e as lideranças do movimento em prol do sufrágio feminino em Londres na década de 1910.

Os arranjos socioculturais, além do próprio modelo de negócios, que fizeram das práticas de consumo nas lojas de departamentos uma atividade essencialmente feminina serviram também para assinalar e reforçar uma divisão sexual de tarefas nos dois polos básicos do sistema capitalista - a produção e o consumo. A produção, esfera da luta política, algo que demanda força, energia e vigor, é dominantemente percebida como masculina; o consumo, esfera da experiência prazerosa

7 Gordon Selfridge serviu ainda de inspiração para o dramaturgo Harvey Granville-Barker escrever um dos principais personagens da peça de teatro pró-sufrágio feminino Madras House, de 1911 (NAVA, 2007). 
do apelo às emoções, magia e fetiche, é dominantemente percebido como feminino.8 A percepção dessas duas esferas - masculina uma e feminina outra - não impediu que a luta política se processasse nos espaços de consumo, de certa forma capazes de controlar a atividade feminina. Neles, cuja principal função era oferecer lazer e deleite às mulheres, 9 a atuação política, paradoxalmente, prosperou. As sufragistas se valeram de possibilidades que se prestavam ao seu controle exatamente para escapar dele, estabelecendo o início de uma parceria profícua entre feminismo e consumo que se repetiu em alguns outros episódios registrados na história de suas lutas.

Esse foi o caso também da parceria desenvolvida entre o cigarro e a liberdade feminina, mais particularmente concretizada nas ações que aconteceram nos Estados Unidos em torno da marca Lucky Strike no início do século XX. O evento, publicitário por um lado, libertário por outro, foi uma marcha que ficou mundialmente conhecida como Torches of Freedom, que reuniu feministas na famosa Fifth Avenue, em Nova York, para que todas juntas, em um ato de rebeldia, acendessem seus cigarros, demonstrando que a mulher podia frequentar o espaço público e, ainda por cima, cultivar hábitos semelhantes aos masculinos. É importante frisar que, até então, o tabagismo era proibido para as mulheres e servia para demarcar fortemente as diferenças entre o que homens e mulheres podiam fazer:

[...] o momento do fumo separava homens e mulheres, promovendo uma organização do espaço que tanto refletia quanto engendrava os papéis sociais de cada gênero: após um jantar, enquanto elas iam para a cozinha preparar a sobremesa, eles fumavam em seus escritórios [...] (LEAL; FREIRE FILHO; ROCHA, 2016, p. 53).

As mulheres norte-americanas já haviam conquistado o direito ao voto e estavam frequentando espaços públicos de maneira mais significativa

8 Para ampliar a discussão a respeito das diferenças entre a produção como masculina e o consumo como feminino, ver o texto de Stephen Brown (2000).

9 Não por acaso, a escolha do título O paraíso das damas (Au Bonheur des Dames) para o romance de Émile Zola que tem como cenário uma loja de departamentos em Paris. 
no final da década de 1920, muito em razão do uso da bicicleta. Para elas, o cigarro era um importante símbolo em seu processo de emancipação. E, na conjuntura que reuniu ascensão da cultura do consumo e American way of life, as empresas tabagistas e os movimentos feministas alinharam seus interesses: um motivado pelo imenso potencial de mercado, outro pela expressividade política que o ato de fumar em público acarretava.

Assim, foi organizada, em 1929, a propósito da Easter Sunday Parade, uma ação de vendas que articulou liberdade feminina e abertura do mercado tabagista para as mulheres que desfilaram com suas "tochas da liberdade” (os cigarros Lucky Strike) acesas. O evento obteve ampla cobertura jornalística e provocou um debate de abrangência nacional.

A marcha, é claro, apresenta a particularidade de ter sido orquestrada por Edward Bernays, 10 um profissional da área de comunicação e vendas que trabalhava para uma marca de cigarros. Mas talvez esse também tenha sido o caso do tino comercial de Gordon Selfridge em suas lojas. Entretanto, essas estratégias de vendas, se existiram, só foram possíveis por força de uma parceria - o consumo e o movimento de mulheres -, pois endossar a presença feminina comprando nas lojas ou fumando nas ruas era de interesse mútuo.l1 Assim, seja em razão das forças que movem o consumo ou daquelas que movem as lutas feministas, a análise de certos fenômenos de consumo deve passar por uma perspectiva livre de reducionismos que não oponha necessariamente práticas políticas e mercadológicas. De fato, pontos de contato profícuos e recíprocos significaram oportunidades históricas para ambas - tanto nas compras nas lojas de departamentos quanto fumando cigarros nas ruas. O que veremos a seguir é como outro bem de consumo - agora, a politicamente correta bicicleta - foi também capaz de reunir interesses de mercado com a liberdade feminina de movimento e autonomia do corpo.

10 Sobrinho de Freud e pioneiro nas relações públicas que escreveu o primeiro livro e lecionou o primeiro curso universitário sobre o tema (CESCA, 2012).

11 As motivações dos produtores, sejam sustentadas apenas em seus interesses de mercado, sejam sustentadas pelo efetivo comprometimento com a causa feminina, serão objeto de análise em pesquisa futura. 


\section{Bicicletas e liberdade}

Bens de consumo concretos ou mesmo o fenômeno como um todo podem, em determinados momentos históricos, aparecer articulados às forças que lutaram por liberdades políticas - o direito ao voto - ou disputaram hábitos culturais - a possibilidade de fumar em público. $\mathrm{O}$ consumo, portanto, não é mero efeito reflexo da produção, nem simples suporte para diferenciação social e exercícios do poder. De fato, quando um produto ou serviço resultante do jogo do mercado e das forças produtivas passa a fazer parte da ordem cultural, um complexo leque de significados se abre e uma multiplicidade de leituras passa a ser possível por parte dos atores sociais. É evidente que essas leituras são condicionadas pela própria "função" do bem, uma vez que seria de difícil sustentação uma leitura que fizesse um sabonete, por exemplo, ser parte de uma refeição. Também essas leituras são condicionadas pela narrativa publicitária que dá tanto o nome quanto define a identidade do bem de consumo (BAUDRILLARD, 1991; BARTHES, 2003; ROCHA, 1985). Entretanto, um produto ou serviço pode adquirir significados não previstos por sua "função" nem pela narrativa publicitária. Esse foi o caso da bicicleta, cuja "função" evidente é transportar e assim foi moldada pela publicidade.

O ponto é que a bicicleta foi muito além como suporte de significados e permitiu leituras mais complexas e polêmicas que suas incontáveis possibilidades como veículo. A bicicleta, redundância à parte, transportou muito mais do que se previa e provocou transformações significativas na vida pública e política das mulheres. Mais que veículo, diversão ou algo benéfico à saúde, tornou-se suporte de uma verdadeira transformação sociocultural e, em algumas décadas, se transformou em agente ativo do movimento feminista. Não por acaso, a sufragista Susan Anthonyl2 expressou, de maneira emblemática, o vínculo da bicicleta com o movimento: "Deixe-me dizer o que eu penso sobre a bicicleta. Eu penso

12 Susan Anthony é reconhecida, ao lado de Elizabeth Staton, como pioneira na atuação política feminista nos Estados Unidos da América. Organizou a $1^{\text {a }}$ Convenção pelos Direitos das Mulheres em 1848 e participou da criação da National Womam Suffrage Association em 1869 (HARPER, 1906). 
que ela fez mais para a emancipação feminina do que qualquer outra coisa no mundo. Eu paro e me regozijo toda vez que vejo uma mulher pedalando" (ANTHONY, 1896, p. 10, tradução nossa).

Antes de avançar nessa direção, é importante conhecer alguns marcos históricos para melhor compreender o impacto da invenção da bicicleta. Como de resto acontece com quase todas as invenções relevantes, as atribuições de autoria dos primeiros modelos de bicicleta são bastante diversas. No entanto, é comum reconhecer pelo menos três "modelos clássicos”, por assim dizer, de antecessores da bicicleta moderna. O primeiro seria um rascunho de Leonardo da Vinci e, em que pese o fato de que, até onde se sabe, jamais saiu do papel, é por si só suficiente para que a bicicleta ganhe uma genealogia nobre e heroica (SCHETINO, 2007). Outro protótipo igualmente famoso recebeu o nome de Laufmaschine, 13 porém ficou mais conhecido como Draisiana. Inventado em 1817 pelo barão de Drassler, na Alemanha, o modelo chegou a ser produzido, mas difere bastante da "nossa" bicicleta, pois se tratava de um artefato cuja utilização era restrita às descidas, já que consistia em estruturas rígidas de madeira presas às duas rodas, com eixo de direção fixo e sem pedais (VERDÚ, 2017).

Somente em 1861 os irmãos Pierre e Ernest Michaux desenvolveram um novo modelo de veículo de duas rodas que parece mais próximo da bicicleta: ao inserir pedais no aro da roda dianteira e, acima dela, fixar um guidom, os criadores da Veló Michaux permitiram ao condutor algum controle sobre o veículo (SCHETINO, 2007). Pouco mais de uma década após a invenção dos irmãos Michaux, um novo modelo inglês de bicicleta chama atenção - disputando com o telefone de Graham Bell e o ketchup Heinz - dos visitantes da Exposição Universal de 1876, acontecida na Filadélfia, nos Estados Unidos (MACY, 2011). Tratava-se da high wheelers, mais conhecida na Grã-Bretanha como penny farthings em razão do seu formato, que remetia a duas moedas: o farthing - a roda menor - e o penny - a roda maior, onde ficavam fixados os pedais, o selim e o guidom. O modelo era visualmente atraente, mas difícil de 
subir e perigoso, pois a possibilidade de cair era iminente (STRANGE; BROWN, 2002).

Entre os muitos visitantes da Exposição Universal, Albert Pope fica especialmente interessado naquela nova forma de locomoção em duas rodas. Porém, só decide investir no produto quando, na primavera seguinte, foi surpreendido, durante um passeio a cavalo, ao ser ultrapassado por alguém que se locomovia em high wheelers (MACY, 2011). Pope percebe a força da invenção - o potencial contido nesse futuro bem de consumo - e fabrica a primeira versão norte-americana do modelo mostrado na Exposição Universal. Seu projeto, entretanto, esbarra na questão das patentes, que já regulavam tanto invenções quanto nomes, marcas e lançamentos de produtos. A solução foi investir na compra das patentes, fundando, em 1878, a Columbia, primeira marca de bicicletas dos Estados Unidos da América (MACY, 2011). Esse é o momento no qual o grande público toma contato com o bem de consumo cujo impacto repercutiu na esfera política ao se tornar um dos símbolos do movimento feminista. A horseless carriage, como chamada nos Estados Unidos, ou o cheval de fer, como conhecida na França, vai se tornar arena de lutas por direitos, pelo uso dos corpos, das sensibilidades e ser objeto de disputas de poder de impactos não previstos (STRANGE; BROWN, 2002).

Por falar em cavalo, um aspecto importante sobre interdições aos usos dos corpos femininos - abrir as pernas e cavalgarl4 - se estendeu à bicicleta e, corroborando a norma vigente, os primeiros modelos femininos da high wheelers tinham os dois pedais fixados do mesmo lado da roda, o que resultava em um equilíbrio precário. Todavia, a despeito desse "ajuste moral", as mulheres norte-americanas encararam o desafio e pedalaram assim mesmo (MACY, 2011).

Além das leis da física, as mulheres enfrentaram muitas outras dificuldades, pois argumentos de toda a sorte tentaram afastá-las do novo bem de consumo. Até mesmo entre elas, a bicicleta escandalizou e gerou

14 Não era recomendada às mulheres a prática da montaria; quando inevitável, elas não deviam se sentar de pernas abertas sobre o cavalo, tendo sempre de montar "de lado" no animal (PONTES e PEREIRA, 2014). 
críticas pesadas, como a de Charlotte Smith, uma das fundadoras da Women's Rescue League, ao dizer que: "[...] a bicicleta é um agente do avanço demoníaco moral e fisicamente em várias instâncias” (SMITH, 1896a, p. 1, tradução nossa). Porém, a crítica mais consistente e respeitada era a "científica", provinda do discurso médico, que, em linhas gerais, condenava o uso do novo bem de consumo por trazer prejuízos físicos e de saúde, incluindo infertilidade ou, ainda pior, por criar formas de excitação sexual (MELO e SCHETINO, 2009). O discurso médico a respeito da bicicleta refletia menos questões de saúde do que a ideologia de controle sobre comportamentos e corpos femininos:

As advertências médicas em torno da bicicleta eram essencialmente uma extensão das preocupações com as mulheres. A necessidade de uma estreita supervisão dos hábitos de ciclismo feminino, frequentemente repetida por profissionais médicos de ambos os sexos, veio em resposta à ameaça que a liberdade feminina representou para a autoridade convencional. [...] Além disso, o nível de interesse expresso no impacto do ciclismo na capacidade reprodutiva feminina reflete a expectativa do papel das mulheres na época. Como o ciclismo tinha o potencial de evitar que elas cumprissem seus papéis primários como esposas e mães, foi criticado como inapropriado e perigoso (FLEMING, 2015, p. 15, tradução nossa).

A relação entre o público feminino e a bicicleta foi complexa. $\mathrm{Na}$ virada do século XIX para o XX, o novo bem de consumo foi capaz de colocar em questão um conjunto de práticas e ideologias de controle social sobre a mulher. A bicicleta permitia à mulher se movimentar entre espaços não vigiados ou destinos predeterminados, o que acabava dando curso a uma liberdade de escolha indesejada pelo poder vigente. Também ameaçava controles sociais sobre seus corpos e desejos, que não seriam mais tão devidamente domesticados, pois abrir as pernas, ter um selim entre elas e pedalar era algo além do limite do admissível, algo que, como diziam médicos, poderia redundar em excitações sexuais descontroladas e significativos prejuízos ao confinado lugar de esposa e mãe. A bicicleta ameaçou muita coisa, mas era parte do processo de industrialização e da sua contraparte, o consumo. Implicou, portanto, 
um choque no qual o conjunto de arranjos culturais que deu espaço aos movimentos pelas liberdades femininas teve no consumo um elemento compatível.

Mas, nesse sentido, é possível ir ainda além. Os objetos e bens de consumo existem em sistema e fazem parte de uma linguagem na qual os termos devem ser compatíveis, como há muito ensinou Baudrillard (1968). A bicicleta era um termo forte e implicou o rearranjo ou a criação de outros tantos bens de consumo na formação de um conjunto próprio que passaria a harmonizar os múltiplos bens que se instituíram em torno dela. Quando um bem de consumo encontra lugar na vida social, acarreta tanto o reordenamento dos demais quanto o aparecimento de outros que deverão se agregar em uma gramática na qual os termos são interdependentes e todos desejados pelo público. No caso específico das mulheres, os novos bens que se agregam visam superar as inúmeras dificuldades postas pelo uso da bicicleta, sobretudo as relativas ao vestuário. As peças de roupas então disponíveis - incômodos espartilhos, inúmeras anáguas ou longas saias - praticamente inviabilizavam as pedaladas e eram nada coerentes com o uso do novo bem.

Como parte dessa dinâmica de criação ou rearranjo dos bens de consumo, uma insólita peça de vestuário criada na década de 1850 voltou à cena com força total: as Turkish trousers, uma espécie de "ceroula" feminina, isto é, uma calça que se prendia aos tornozelos e deveria ser usada por baixo de saias ligeiramente mais curtas (Turkish skirts) que as tradicionais. Como indica o nome, era muito usada pelas mulheres turcas e, nos Estados Unidos, tornou-se conhecida como bloomers, em homenagem a uma de suas grandes entusiastas, a jornalista e feminista Amelia Bloomer (MACY, 2011).

A bicicleta abriu um sistema de bens de consumo no qual as bloomers começaram a ser justificadamente demandadas e ganharam popularidade. A entrada das bloomers no cotidiano das norte-americanas, entretanto, não foi fácil, pois ver mulheres usando calças e vestidos bem mais curtos escandalizou a sociedade. Os limites impostos pela vestimenta contribuíam para que a mulher burguesa permanecesse 
restrita aos ambientes domésticos e bem diferenciada de qualquer coisa que recendesse às atividades masculinas. Mesmo os trabalhos para essas mulheres burguesas eram poucos e, com exceção do magistério, se restringiam a atividades subalternas (STRANGE; BROWN, 2002). Muitas professoras, por exemplo, foram proibidas de usar bicicleta, pois as bloomers poderiam "confundir" a cabeça dos alunos. Como declarou ao New York Times um diretor de escola, “[... estamos determinados a parar nossas professoras em tempo antes que cheguem longe demais" (REIMER, 1895, p. 1, tradução nossa).

As bloomers, por se encaixarem no novo sistema de bens de consumo, receberam forte apoio da marca de bicicleta Columbia, que passou a inserir mulheres de bloomers nos anúncios publicitários e lançou, ainda, uma série de paper dolls15 cujas peças incluíam bicicletas e bloomers (MACY, 2011). Com essa "ação de marketing" avant la lettre, a Columbia buscava também o público infantil, futuras consumidoras de bicicletas e dos demais bens do sistema que ela ativava. Também nas roupas, portanto, o consumo e o movimento de mulheres que lutava por sair da condição de subordinação encontraram interesses em comum. A bicicleta forçou transformações culturais importantes para a vida da mulher na passagem do século XIX para o XX e, além das bloomers, outras peças de vestuário - "[...] calcinhas, [...] chapéus mais simples e saias com fendas” (DEMPSEY, 1977, p. 29, tradução nossa) - foram adaptadas pela força da bicicleta como bem de consumo.

Contudo, o mais importante aspecto dessa transformação de valores está no fato de que a bicicleta permitiu à mulher estabelecer uma nova relação com o espaço público, afinal “[...] a bicicleta representava um desafio para a doutrina das esferas separadas [entre público e privado] por oferecer às mulheres uma maneira de escapar ao confinamento do lar” (STRANGE; BROWN, 2002, p. 616, tradução nossa). Não por acaso, diversos pesquisadores (MACY, 2011; STRANGE; BROWN, 2002; MELO; SCHETINO, 2009) enfatizam esse bem de consumo como um

15 Brinquedo de meninas que consiste em uma personagem feminina recortada em cartolina e acompanhada de peças de roupas, também de papel, que podem ser vestidas e trocadas pela criança. 
agente das transformações na condição feminina no princípio do século passado, favorecendo, em última instância, a participação política, traduzida em direito ao voto e à formação acadêmica.

A bicicleta foi defendida, utilizada e exaltada por grandes nomes da primeira onda feminista nos EUA, como Elizabeth Staton e Susan Anthony, que afirmavam que esse veículo era um emancipador de mulheres (STRANGE; BROWN, 2002). Consagração semelhante pôde ser observada entre as suffragettes francesas no início do século XX (MELO; SCHETINO, 2009). Na Grã-Bretanha, a campanha de 1897 que pedia a entrada definitiva de mulheres na Universidade de Cambridge foi promovida através de panfletos com a ilustração de uma mulher pedalando uma bicicleta (MACY, 2011).

\section{Considerações finais}

Ao aproximar a temática feminista dos estudos sobre as representações e práticas de consumo, iluminando suas parcerias inusitadas, buscamos realizar uma leitura histórica e crítica e que, portanto, se propõe distante do "paradigma do tribunal" (ROCHA, 1995), que, como vimos, se faz frequente nos estudos de comunicação social.

Dessa maneira, foi possível identificar em algumas situações consolidadas na nossa história recente indicativos de que o feminismo e as práticas de consumo concertaram alianças que traduziram um recíproco espalhamento de suas ideologias. Ao relativizar moralismos em face dessa associação de polos, frequentemente tratados como incompatíveis, pode-se constatar coisa bem diferente - a transformação da condição feminina foi também percorrida pela via do consumo. A conquista do espaço público e a maior participação política se consolidam em fatos que falam por si: mulheres em suas bicicletas engendraram modificações nos poderes de sua época, nos vestuários, nos costumes, nas sensibilidades. Lojas de departamentos, cigarros acesos nas ruas, calças apertadas nas pernas e bicicletas teceram uma complexa teia de valores que, no mesmo gesto, reuniu consumo e luta política; compra e sufrágio; bens e pessoas. 


\section{Referências}

ADORNO, T. A indústria cultural. In: COHN, Gabriel (Org.). Comunicação e indústria cultural. São Paulo: Companhia Editora Nacional, 1971 [1968].

ADORNO, T. Résumé über Kulturindustrie. In: . Ohne Leitbild - Parva Aesthetica. Frankfurt am Main: Suhrkamp Verlag, 1968. p. 60-70.

.; HORKHEIMER, M. Dialética do esclarecimento. Rio de Janeiro: Zahar, 1997 [1947].

AMOS, A.; HAGLUND, M. From social taboo to "torch of freedom": the marketing of cigarettes to women. Tobacco Control, BMJ Publishing Group, 2000.

ANTHONY, S. B. Champion of her sex. New York Sunday World, Nova York, p. 10, 1986.

BARTHES, R. Mitologias. São Paulo: Difel, 2003 [1957].

BAUDRILLARD, J. A sociedade de consumo. Lisboa: Edições 70, 1991 [1970]. Le système des objets. Paris: Gallimard, 1968.

BAUER M.; GASKELL G. Pesquisa qualitativa com texto, imagem e som. Petrópolis: Vozes, 2002.

BROWN, S. The laugh of the marketing Medusa: men are from Marx, women are from Veblen. In: CATTERALL, Miriam; MACLARAN, Pauline; STEVENS, Lorna. Marketing and feminism: current issues and research. Londres: Nova York: Routledge, 2000.

BUENO, M. L. Apresentação: cultura e estilos de vida. In: BUENO, L.;CAMARGO, L. O. (Orgs.). Cultura e consumo: estilos de vida na contemporaneidade. São Paulo: Senac, 2008.

BURKE, P. Modernidade, cultura e estilos de vida. In: BUENO, L.; CAMARGO, L. O. (Orgs.). Cultura e consumo: estilos de vida na contemporaneidade. São Paulo: Senac, 2008.

CESCA, C. G. G. Relações públicas para iniciantes. São Paulo: Summus, 2012.

COX, P. Shop girls, social history and social theory. Revista Brasileira de História, São Paulo, v. 37, n. 75, p. 243-271, 2017.

DEMPSEY, P. The bicycler's bible. Nova York: Tab Books, 1977.

DUARTE J.; BARROS A. Métodos e técnicas de pesquisa em comunicação. São Paulo: Atlas, 2009.

ECO, U. Apocalípticos e integrados. São Paulo: Perspectiva, 1979 [1964].

FLEMING, J. E. The bicycle boom and women's rights. The Gettysburg Historical Journal, v. 14, p. 13-26, 2015.

HARPER, I. H. Susan B. Anthony: the woman and her work. The North American Review (NAR), v. 182, n. 593, p. 604-616, 1906.

LEAL, T.; FREIRE FILHO, J.; ROCHA, E. Torches of freedom: mulheres, cigarros e consumo. Comunicação, Mídia e Consumo, São Paulo, v. 13, n. 38, p. 48-72, set.-dez. 2016.

MACY, S. Wheels of change: how women rode the bicycle to freedom (with a few flat tires along the way). Washington: National Geographic, 2011. 
MARTINO, L. M. S. Teoria da comunicação: ideias, conceitos e métodos. Petrópolis: Vozes, 2010.

MCCRACKEN, G. Cultura e consumo: novas abordagens ao caráter simbólico dos bens e das atividades de consumo. Rio de Janeiro: Mauad X, 2003.

MELO, Victor Andrade de; SCHETINO, André. "A bicicleta, o ciclismo e as mulheres na transição dos séculos XIX e XX”. In: Estudos Feministas. Florianópolis, 17. v. 1. Janeiro/abril, 2009. p. 111-134.

NAVA, M. Visceral cosmopolitanism: gender, culture and the normalization of difference. Nova York: Berg, 2007.

PONTES, V. S.; PEREIRA, E. G. B. Sob rédeas curtas, de cabelos longos: reflexões sobre mulheres no hipismo. Movimento, Porto Alegre, v. 20, n. 3, p. 1.197-1.222, jul.-set. 2014.

RAPPAPORT, E. Uma nova era de compras: a promoção do prazer feminino no West End Londrino 1909-1914. In: CHARNEY, L.; SCHARTZ, V. R. (Orgs.). O cinema e a invenção da vida moderna. São Paulo: Cosac Naify, 2004. p. 157-184.

REIMER, A. F. W. Object to women bicyclists; College Point School Trustees say they must not ride to and from their duties. New York Times, p. 1, 15 jun. 1895.

ROCHA, E. A sociedade do sonho: comunicação, cultura e consumo. Rio de Janeiro: Mauad X, 1995.

. Culpa de prazer: imagens do consumo na cultura de massa. Comunicação, Mídia e Consumo, São Paulo, v. 2, n. 3, p. 123-138, 2005.

Magia e capitalismo: um estudo antropológico da publicidade. São Paulo: Brasiliense, 1985.

.; FRID, M.; CORBO, W. A corte, o chá e o voto: o consumo como arena política. Intexto, v. 34, p. 322-341, 2015.

O paraíso do consumo: Émile Zola, a magia e os grandes magazines. Rio de Janeiro: Mauad X: PUC-Rio, 2016.

SCHETINO, A. M. Ciclismo e modernidade: apontamentos sobre a invenção da bicicleta e os primórdios do ciclismo no Rio de Janeiro. In: SIMPÓSIO NACIONAL DE HISTÓRIA - HISTÓRIA E MULTIDISCIPLINARIDADE: TERRITÓRIOS E DESLOCAMENTOS, XXIV, 2007, São Leopoldo . Anais... São Leopoldo: Unisinos, 2007. SMITH, C. Is bicycling immoral? Woman's Rescue League says it is. Brooklyn Eagle, p. 1, 19 ago. 1896a.

. Warns against the wheel. New York Journal, p. 9, 5 out. 1896b.

STONE, L. The clothes that kill. Wood River Times, Hailey, p. 1, 19 ago. 1887.

STRANGE, L. S.; BROWN, R. S. The bicycle, women's rights, and Elizabeth Cady Stanton. Women's Studies, v. 31, p. 609-626, 2002.

VERDÚ, R. C. La emancipación femenina decimonónica a través del denuedo velocipédico. Femeris: Revista Multidisciplinar de Estudios de Género, v. 2, n. 2, p. 119-136, 2017.

ZOLA, É. O paraíso das damas. São Paulo: Estação Liberdade, 2008. 


\section{Sobre a autora e 0 autor}

Everardo Rocha - Professor associado do Departamento de Comunicação Social da Pontifícia Universidade Católica do Rio de Janeiro (PUC-Rio). Doutor em Antropologia Social pelo Museu Nacional da Universidade Federal do Rio de Janeiro.

Beatriz Beraldo - Doutoranda do Programa de Pós-graduação em Comunicação da PUC-Rio. Mestre em Comunicação e Práticas de Consumo pela Escola Superior de Propaganda e Marketing de São Paulo (ESPM SP). Professora horista do curso de graduação em Comunicação Social da Uni-IBMR.

Data de submissão: 30/04/2018

Data de aceite: 02/10/2018 